ISSN-PRINT 1794-9831 / E-ISSN 2322-7028

Vol. 18 No 2 / Mayo - Agosto, 2021 / Cúcuta, Colombia.

doi) https://doi.org/10.224663/17949831.2782

Original

\title{
La comodidad para el paciente crónico desde el sentir y el hacer ${ }^{\dagger}$
}

\section{Comfort for the chronic patient from their feelings and actions \\ $O$ conforto para o paciente crônico desde o sentir e o fazer}

\author{
Yadira Cardozo-Garcia ${ }^{1}$ \\ Angela Maria Salazar-Maya ${ }^{2}$ \\ Carmen Liliana Escobar-Ciro ${ }^{3}$
}

\section{Resumen}

Objetivo: Describir el significado de comodidad para los pacientes con enfermedad crónica que se encuentran hospitalizados en una institución de tercer nivel de complejidad de la ciudad de Medellín. Materiales y métodos: Estudio cualitativo con enfoque etnográfico. Se realizaron quince entrevistas y cuarenta horas de observación participante. Los participantes fueron los pacientes con enfermedad crónica, hospitalizados en el servicio de medicina interna en una institución de la ciudad de Medellín (Colombia). Para el análisis se realizó una lectura y relectura de los relatos; mediante su codificación se identificaron los conceptos para categorizarlos, relacionando las categorías con sus respectivas subcategorías. Resultados: El significado que construye el paciente con enfermedad crónica acerca de la comodidad es un concepto muy amplio, en el que se consideran aspectos del entorno, físicos, sociales, emocionales, socioculturales. Los mismos deben ser considerados durante la atención para lograr el bienestar del paciente y del cuidador durante el tiempo de hospitalización. Conclusiones: La comodidad es un componente del cuidado que se debe suplir por la enfermera. Al respecto es importante comprender las formas y los medios para brindar comodidad a los pacientes hospitalizados, con el fin de lograr el mayor estado de bienestar en ellos durante su estancia en el hospital. A su vez las instituciones hospitalarias deben escuchar la voz del paciente con el fin de realizar las adecuaciones pertinentes, a fin de hacer que la experiencia de hospitalización sea grata y lo menos traumática posible para los pacientes con enfermedad crónica.

Palabras clave: Comodidad del paciente, enfermedad crónica, hospitalización, atención de enfermería, etnografía, teoría de enfermería.

\section{Autor de correspondencia*}

$\mathbf{1}^{*}$ Enfermera, Magister en Educación y Desarrollo Humano, profesora asociada Facultad de Enfermería Universidad de Antioquia, Medellín - Colombia. Correo: yadira.cardozo@udea.edu.co. (1D) $\underline{0000-0003-2588-5717}$

${ }^{2}$ Enfermera, Doctora en Enfermería profesora titular Facultad de Enfermería Universidad de Antioquia, Medellín -Colombia. Correo: Angela.salazar@ $\underline{\text { udea.edu.co (i) 0000-0001-7599-1193 }}$

${ }^{3}$ Enfermera, Magister en enfermería, profesora ocasional asistente Facultad de Enfermería Universidad de Antioquia Medellín - Colombia. Correo: carmen.escobar@udea.edu.co (iD 00000002-6296-0280

† Artículo producto de la investigación titulada: Significado de la comodidad para los pacientes con enfermedad crónica hospitalizados en un servicio de medicina interna.

Recibido: 25 noviembre 2020 Aprobado: 8 abril 2021

Para citar este artículo / To reference this article / Para citar este artigo:

Cardozo-García Y, Salazar-Maya AM, Escobar-Ciro CL. La comodidad para el paciente crónico desde el sentir y el hacer. Rev. cienc. cuidad. $2021 ; 18(2): 19-32$. https://doi org/10.22463/17949831.2782

(C) Universidad Francisco de Paula Santander. Este es un artículo bajo la licencia CC-BY-NC-ND pects. These must be considered during the health care provided to achieve welfare for the patient and the caregiver during the hospitalization time. Conclusions: cComfort is a care component that the nurse must provide. Thereon, it is important to understand the means and

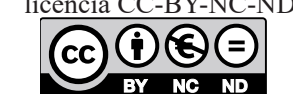


Scientific Journal of Nursing

ways to provide comfort to hospitalized patients, in order to achieve greater welfare of the patients during their stay at the hospital. Likewise, the healthcare institutions should listen to the patients to be able to make adequate adjustments for a pleasant and less traumatic hospitalization experience for patients with chronic diseases

Keywords: Comfort of the patient, chronic disease, hospitalization, nursing care, ethnography, nursing theory.

\section{Resumo}

Objetivo: Descrever o significado de conforto para os pacientes com doença crônica internados numa instituição de alta complexidade da cidade de Medellín. Materiais e métodos: Estudo qualitativo etnográfico. Realizaram-se 15 entrevistas e quarenta horas de observação participante. Os participantes foram os pacientes com doença crónica internados na enfermaria de clínica médica numa instituição de Medellín na Colômbia. Na análise realizou-se a leitura e releitura dos relatos; através de sua codificação identificaram-se s conceitos e categorizaram-se, relacionando categorias e subcategorias. Resultados: O significado que constrói o paciente com doença crônica sobre o conforto é amplo e diverso, considerando o entorno físico, social, emocional e cultural. Os mesmos devem ser considerados durante o atendimento para conseguir o bem-estar do paciente e o cuidador durante o tempo de internação. Conclusões: $\mathrm{O}$ conforto faz parte do cuidado que fornece enfermagem. A compreensão das formas e médios para prestar conforto aos pacientes internados, com o propósito de proporcionar o maior estado de bem-estar neles durante a permanência hospitalar. Além disso, as instituições hospitalares devem prestar atenção aos requerimentos dos pacientes com o propósito de realizar as adequações necessárias para fazer da experiência de internação um período gratificante e menos traumático para os pacientes com doença crônica.

Palavras-chave: Conforto do paciente, doença crônica, internação, cuidados de enfermagem, antropologia cultural, teoria de enfermagem.

\section{Introducción}

Las enfermedades crónicas no transmisibles (ECNT) son de alta incidencia y mortalidad en el mundo; en los países en vía de desarrollo representan cerca del 75\% de las causas por muerte. Estas se caracterizan por ser de larga duración y de evolución lenta, con periodos estables y de crisis; estos altibajos llevan a un desgaste y degeneración funcional progresiva de la persona (1). El análisis de situación de salud (ASIS) reportó que en el período de 2009 a 2018 el 65,4\% de la prestación en salud fue para personas con ECNT (2). En la ciudad de Medellín las ECNT se encuentran dentro de las primeras causas de morbilidad y mortalidad (3).

Se debe precisar que los pacientes con enfermedad crónica, en muchos casos, debido a la descompensación de la enfermedad requieren de la hospitalización para la estabilización de esta, lo cual los lleva en ocasiones a estancias hospitalarias recurrentes y/o prolongadas que exigen de servicios especializados y de la atención mul- tidisciplinaria. Ante esta situación es importante señalar que la comodidad es un factor decisivo y puede definirse como la ausencia de sensaciones desagradables, tanto físicas como emocionales; por tanto es algo subjetivo y personal (4). Es por ello que surge la necesidad de conocer la apreciación del paciente acerca de lo que significa para él la comodidad durante la hospitalización; por tanto, es quien debe manifestar su bienestar o malestar con la atención recibida (5). De ahí, que la comodidad ha sido considerada un aspecto de relevancia a la hora de brindar el cuidado, puesto que impacta sobre la calidad de vida de las personas y facilita el mantenimiento y recuperación de la salud $(6,7)$.

A su vez, la calidad de los servicios no solo está relacionada con los aspectos científicos y técnicos, sino con la experiencia expresada por los pacientes en relación con las necesidades de afecto, comprensión, protección, bienestar, ocio e información (8).

Aun cuando en la enfermería se habla de comodidad, 
es importante orientar las intervenciones para satisfacer la necesidad de comodidad, no solo desde un enfoque biológico, sino que además, debe estar centrada en el paciente y la familia, donde al hospital se le considera como el hogar, haciendo que la situación de salud sea algo más llevadero; es decir, que el hospital debe ser un lugar humano y cálido (9). Desde este punto de vista, es importante atender las necesidades del paciente a partir de las experiencias vividas por éste, lo cual implica la escucha, la aclaración de dudas, la interacción y la comunicación positiva. De igual forma hay que tener presente la integración de la familia para que participe en el cuidado, el alivio de las molestias, el respeto por las decisiones, entre otras; todos estos factores hacen parte del cuidado holístico y confortable (10). Es así como el bienestar se materializa en sensaciones de carácter físico, psicológico, espiritual y ambiental, que perfilan las dimensiones más objetivas del confort como fenómeno (11).

\section{Objetivo general}

Describir el significado de comodidad para los pacientes con enfermedad crónica que se encuentran hospitalizados en una institución de tercer nivel de complejidad de la ciudad de Medellín.

\section{Materiales y métodos}

Se trata de un estudio cualitativo con enfoque etnográfico, focalizado o microetnografia, que se caracteriza por centrarse en pequeños subsistemas culturales (12). Se planteó como objetivo indagar por el significado de la comodidad para el paciente con enfermedad crónica durante febrero de 2018 a octubre de 2019. Al respecto, Almudena Cotán Fernández considera que la etnografía se interesa por describir, analizar y comprender el funcionamiento de las culturas y lo que sucede en ellas (13).

Una vez que el proyecto fue aprobado por el Comité de ética y el científico de la institución se inició la investigación, utilizando como muestra representativa a las enfermeras de los servicios de hospitalización, a quienes se les informó sobre la investigación y su objetivo. El estudio se inició con la observación en los servicios de medicina interna y con la participación de los pacientes con EC y su familia, lográndose establecer una relación de empatía o rapport (14), lo que permitió informarles sobre la investigación y su objetivo, facilitando la participación voluntaria.

Se realizaron 15 entrevistas a 14 participantes hospitalizados en una institución de tercer nivel. El tiempo empleado tuvo un promedio de 2 horas por participante. Se utilizaron preguntas orientadoras abiertas, teniendo en cuenta los objetivos de la investigación, con el fin de obtener un proceso interactivo con los participantes (15). Hay que aclarar, que se entrevistó nuevamente a uno de los participantes, ya que durante la hospitalización se le ubicó en dos servicios con condiciones diferentes en la infraestructura. Las entrevistas se realizaron en las habitaciones de los pacientes; las mismas fueron grabadas en un medio magnético y posteriormente se transcribieron, para garantizar la confiabilidad de los datos.

Igualmente, se realizaron 40 horas de observación participante (16) en la que se captó la interacción del personal de enfermería con el paciente, con el objetivo de observar las prácticas de confort y comodidad. Además, durante la observación se tuvieron en cuenta los espacios, los actores, los objetos, los eventos que suceden en el entorno hospitalario y los sentimientos relacionados con las emociones expresadas y las emociones observadas en los actores. También, se tuvo en cuenta la relación enfermera-paciente con respecto a la comodidad en cuanto a: la comunicación verbal (tono de voz, tipo de conversación, experiencias...), la comunicación no verbal (conducta visual, proximidad y distancia, movimientos corporales, tacto...), interés en la interacción y tiempo. Para llevar a cabo esta actividad se contó con una guía de observación, lo que permitió mantener la unidad de criterio.

Así mismo, se tomaron notas de campo complementadas con diarios de campo (17), en donde se registró todo lo tocante con la observación y las entrevistas; todo este proceso se efectuó para evitar omisiones $\mathrm{u}$ olvidos de información que pudiera ser relevante. Además, se escribieron comentarios, considerados útiles para la construcción del texto final.

Por otra parte, para el análisis de la información que se obtuvo, se realizó una lectura y relectura de los datos analizándolos línea por línea; luego se los segmentó sin descontextualizarlos, para así obtener el significado en su conjunto. Esta actividad se fundamentó en los siguientes pasos: 1- se recuperaron los datos asignándoles un código particular; 2- se exploraron los códigos y las categorías que fueron emergiendo y se reclasificaron asignándoles un nuevo nombre; y, 3- se procedió a la generalización y teorización. Mediante esta codificación se identificaron los conceptos para categorizarlos, para seguidamente relacionar las categorías con sus subcategorías (18). Con el objeto de validar la información que se consiguió se aplicó la triangulación metodológica (19) conjugando las entrevistas (grabadas) realizadas a los participantes, las observaciones y los análisis. 
De igual forma se elaboraron diagramas conceptuales que facilitaron la visualización de las categorías y la elaboración del informe final. Durante el proceso se protegió el rigor metodológico considerando los criterios de credibilidad, confiabilidad y transferibilidad (20). La credibilidad se consiguió al obtener resultados verídicos sustentados en las entrevistas grabadas y transcritas textualmente, manteniendo así la fidelidad de las expresiones de los participantes; la confiabilidad se obtuvo mediante la imparcialidad en la interpretación y el análisis de la información; y la transferibilidad, hace referencia a la posibilidad de aplicar y extender los resultados a otros grupos, con características similares.

Durante todo el tiempo de la investigación se respetaron los aspectos éticos básicos sobre beneficencia, no maleficencia, justicia y respeto a la autonomía. Se tuvo en cuenta la resolución 008430 del Ministerio de Salud para la calificación del riesgo, la confidencialidad de la información, la garantía de cuidar la privacidad de los informantes, el respeto a la autonomía al aceptar o no en la participación de la investigación, el uso de los datos con fines académicos y la devolución de los resultados a los participantes e instituciones. Igualmente, se aplicó la Ley 266 de 1996, por la cual se reglamentan los principios que rigen la profesión de enfermería y la Ley 911 del 2004 que dispone la responsabilidad deontológica para el ejercicio de la enfermería en Colombia (21-23).

Al mismo tiempo, a cada participante, se le respetó la decisión de retirarse del estudio en cualquier momento. Además, se garantizó la confidencialidad a los participantes y a la institución, asignando códigos para el análisis y la elaboración del informe final. La investigación no generó ningún riesgo físico, ni psicológico para los participantes; no hubo remuneración económica ni de otro tipo. El proyecto se presentó al Comité de Investigación de la institución otorgando su aval para la ejecución tal como consta en el acta 083.

\section{Resulltados}

\section{Descripción del escenario}

En relación al contexto en el que se llevó a cabo la investigación, la institución tiene un modelo de atención centrado en el paciente y la familia, denominado Sermás; dicho modelo fue implementado en el 2017 dando respuesta a las necesidades de pacientes y familias, donde el ser humano se convierte en el centro y razón del quehacer institucional. Los pacientes con EC se hospitalizan en uno de los bloques en los diferentes servicios que se encuentran ubicados en cada piso. Estos espacios comparten características similares en la infraestructura física y el número de personal asistencial asignado para el cuidado del paciente.

Además, cada piso cuenta con servicios ubicados en dos alas: la sur y la norte, con capacidad para 30 pacientes aproximadamente cada una. Algunos pacientes ocupan habitaciones compartidas y otros individuales, con igual infraestructura y disposición de los espacios. También, existen servicios con características especiales, algunos están ocupados por pacientes VIP, otros por pacientes de hematología y en otro piso se ubican los pacientes con aislamiento.

Conviene indicar, que al personal asistencial que trabaja durante el día se le asignan los servicios que no son especiales, de la siguiente forma: una enfermera para la gestión del servicio, la cual realiza su turno en 12 horas; una enfermera asistencial para realizar los procedimientos y las altas hospitalarias, su jornada depende de las actividades a realizar, puede estar seis u ocho horas. De igual forma, se asignan cinco auxiliares de enfermería, quienes realizan actividades para el confort del paciente y la administración de medicamentos y tienen asignados por turno entre seis o siete pacientes. Además, hay un médico general en las mañanas y en la tarde se responsabiliza un solo médico para las dos alas. Igualmente, un médico internista se encarga de cada ala, puede estar en la mañana o en la tarde.

Se debe agregar, que el personal de apoyo durante el día cuenta con una secretaria por piso, es decir, que atiende las dos alas; también hay una persona de oficios generales, quien se encarga de hacer el aseo.

Con respecto, a los servicios especiales, como el denominado VIP, con capacidad para 29 pacientes, cuenta con: una enfermera para la gestión del servicio durante 12 horas; una enfermera asistencial para realizar los procedimientos y las altas hospitalarias, su jornada depende de las actividades, dispone de seis u ocho horas; cuatro auxiliares de enfermería, quienes realizan actividades para el confort del paciente y la administración de medicamentos, además, tienen asignados por turno seis pacientes. De igual manera, se dispone de: un médico general con turno de 12 horas y en la noche uno por cada dos pisos y un médico internista en el día. Además, como personal de apoyo durante el día se cuenta con una secretaria y dos personas de oficios generales para el aseo.

Se debe agregar, que la institución cuenta con grupos de apoyo para la educación y el entrenamiento en el cuidado, cuando sea necesario para atender algunas situaciones clínicas específicas. 


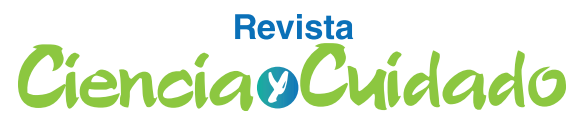

Scientific Journal of Nursing

A continuación, se describen las categorías emergentes, como la comodidad desde el sentir y el hacer y lo que genera incomodad, por otra parte, se les detalla con sus respectivas subcategorías.

\section{La comodidad desde el sentir y hacer}

Para los pacientes la comodidad tiene que ver con el lugar y las personas que le rodean y lo definen; es sentirse bien, estar bien, no estar en peligro; estar bien tanto en lo físico, como desde el punto de vista espiritual. Además, al sentirse escuchados y bien atendidos, no solo por el personal de salud, sino también por el resto de personal que labora en la institución los ayuda a reforzar su comodidad. Es por eso, que la atención que reciben en la institución los hace sentirse cómodos y seguros, es como "sentirse en casa".

De igual forma, el ser autónomos para realizar las actividades de la vida diaria como bañarse, vestirse, alimentarse, caminar los hace independientes y sentirse cómodos.

"Después de que yo me pueda levantar (...) pues sería dificil y maluco cuando uno no puede levantarse ¿sí o no? Pero desde que yo me puede desplazar para cualquier parte gloria a Dios". E1

Por el contrario, depender de los demás, les genera incomodidad y sienten que es un sacrificio, situación que por lo general se vive en los servicios críticos como son el de urgencias y la Unidad de Cuidado Intensivo.

"No, pues yo no. Pues allá en la UCI me limpiaban y todo, porque no me podía mover de la cama. Pero aquí yo ya me puedo parar, ir al baño, bañarme.. E10

Otro factor a tener en cuenta, es que el estar solo da miedo y se prefiere tener compañía, aunque sea del paciente con quien se comparte la habitación; por otro lado, aquellos pacientes que pueden tener al cuidador durante la hospitalización sienten que la estadía es más fácil, sobre todo por la confianza que se les brinda; además, se encuentran más satisfechos durante la estancia hospitalaria.

"lo que no me siento bien es como yo estar sola porque me da mucho miedo, entonces cuando hay una persona ahí que sea como sea, son muy queridas, muy amables, entonces yo me siento satisfecha." E5

Otros aspectos que hacen que el paciente se sienta cómodo tienen que ver con lo físico, es decir, con la ausencia o mejoría de los signos y los síntomas que tenga, específicamente con no experimentar dolor, tener el aire suficiente al respirar, el poder alimentarse cuando su situación de salud va mejorando. Estos aspectos también los relacionan con la comodidad; es decir, el sentirse aliviados y tener calidad de vida.

"Ah, me siento mal cuando tengo el dolor, porque uno con un dolor ahí, no se va a sentir a uno bien." E2

\section{Recursos necesarios para el cuidado}

El hecho de que la institución tenga lo necesario para prestar el servicio asistencial, sin escatimar recursos para brindar la atención, siendo oportuna y eficiente en la prestación de la atención, es importante para los pacientes. Hay que mencionar además, que en relación con la infraestructura y el mobiliario de la habitación, se sienten cómodos cuando cuentan con: una buena silla, una buena cama, el baño en el cuarto, así como el disponer de sus cosas de aseo personal y estar con un familiar, siempre que éste tenga donde dormir y descansar, como lo es un sofacama.

"Para mi pues es cómodo (...) pues lo que tengo apenas es para estar cómoda la cama bien buena, la silla pa' que mi hija se acueste ¿Qué más necesito? El espacio para ir al baño, tengo todo lo suficiente, así sea en un espacio pequeño, pero tengo todo lo que necesito. Sí, porque aquí a pesar de ser tan pequeño está todo, todo lo que yo necesito, no tengo que salir afuera a buscarlo, si no que aqui está (...) me levanto de mi cama y ahí está el baño, ahí está el sanitario. Ahí está mi hija poniéndome cuidado toda la noche". E1

\section{Lo mínimo en comodidad}

Para algunos pacientes las condiciones mínimas tienen que ver con: una buena pintura; ventilación; iluminación; limpieza de la habitación; un baño adecuado y en buenas condiciones; una cama limpia, con preferencia que sea eléctrica, ya que permite hacer los cambios de posición; igualmente, al estar hospitalizados en una habitación individual les permite tener privacidad y descansar.

"muy buena, a mí me han dado habitaciones muy buenas, todos los servicios ahí está todo, ya por la edad mía hay mesita pa que me bañen, porque ya si me da miedo bañarme solo, que de pronto me caiga, siempre me da desaliento los pies". E1

\section{Solicitando atención de enfermería}


Para los pacientes el personal de enfermería realiza actividades que ayudan a la comodidad como son: administrar los medicamentos, hacer cambios de posición, tomar la glucometría y los signos vitales, pasar ronda por las habitaciones, atender algunas necesidades del paciente; sin embargo, reclaman que los enfermeros no están pendientes de actividades básicas como la asistencia en el baño y la alimentación, sobre todo aquellos pacientes con limitaciones o que requieren mayor atención dada su situación de salud.

"como le digo soy discapacitada visual y yo necesito mucho esa ayuda, sí, sería muy bueno que estuvieran pendientes a ver (...) yo la ayudo a bañar". E8

Algunos cuidadores ven al personal de enfermería como colaboradores, pues son quienes prestan ayuda para la realización de algunas actividades durante la hospitalización, como tapar el catéter y tender la cama.

pero si lo único que ella viene, le tapa el catéter y nos ayuda con eso, ella tiende la cama, yo fui y le dije, ay mira necesito un favor, es que no apuntamos ese pipisote en el pipicingo y se mojó la cama usted me da sabanitas, porque ya también sabemos vestir la cama, dijo -no, ya se la voy a cambiar-". E12

\section{Las visitas}

El horario y número de visitantes depende del servicio y la habitación donde se encuentren hospitalizados los pacientes; en las habitaciones compartidas las visitas son más restringidas y solo se permite dos visitantes; en cambio, en las habitaciones individuales, específicamente las de servicios particulares y de planes complementarios, no tienen restricción respecto al número de visitantes y el horario es más flexible; estos factores que inciden directamente sobre la comodidad.

"no yo lo veo excelente porque permitir las visitas las 24 horas a una persona que no es de aqui al acompañante permitirle o darle el acceso para que esté las 24 horas, creo que es una IPS dificil encontrar otra como ésta que preste los mismos servicios". E15

\section{Lo que incomoda}

Para los pacientes hay situaciones que les hace sentirse incómodos, que los afligen y afectan, como: la incomunicación; el resignarse ante aspectos que deben enfrentar en el día a día; la incomodidad que a veces sufren los cuidadores familiares; y la infraestructura física de algunos servicios de hospitalización de la institución. Con respecto a la cama para algunos, no es cómoda y prefieren permanecer sentados en la silla; según expresan, no hay como la cama de la casa.

\begin{abstract}
"Pues sentada, porque en la cama no me siento cómoda o a veces me paro ahí un ratico y me quedo cómoda porque en la cama, no estoy cómoda (...). Eso no sube ni baja y se sienta uno acá y queda como así uno, eso queda como volteado jay sí, muy horrible esta cama!, no es cómoda, en cambio yo en mi cama si me siento demasiado de cómoda. El colchón se baja lo mas de horrible, eso se baja para acá” E3
\end{abstract}

De igual forma, consideran que no hay suficientes sabanas y cobijas para los pacientes, lo que implica que deben llevarlas de la casa.

“Qué no hay sabanas aquí, aquí tienen que estar pues, por allá, trayendo sabanas a ver cuando suben las sabanas, para poder lograr traerlas para que cambien las camas, porque el seguro anda mal de tendidos". E2

La luz prendida toda la noche y el ruido que hace el personal es otro de los aspectos que les genera incomodidad, aspectos que les imposibilita conciliar el sueño.

"A veces si se siente mucha bulla de esos muchachos por ahí gritando y hablando duro". E14

"(la luz) se la dejan prendida a uno toda la noche". E10

\section{Situaciones que afligen y afectan}

Dentro de las situaciones que afligen y afectan a los pacientes está el no ver mejoría en su estado de salud a pesar del tratamiento prescrito, esto los desespera.

"y pues, o sea hace dos días y de ahí para atrás, para mi igual era lo uno o lo otro, porque yo vine a sentir mejoría de ayer para hoy (...) porque si uno no ve progreso de todas maneras, se va desesperando aquí (...) si no hay una respuesta en el tratamiento, eso va desesperando". E7

Por otra parte, el llevar varios días de hospitalización y no ver mejoría en su salud, así como percibir que no se hacen los tratamientos adecuados, son situaciones que afectan al paciente, más cuando lleva años con su enfermedad.

"entonces durante tres dias ni siquiera me hacian pruebas esperando; entonces yo no veía norte, yo decía ¿qué es lo que sigue? "No es que primero tenemos que mirar bien lo de tu enfermedad", yo decía sí, si yo lo entiendo, pero yo creo que para ver lo 
de la enfermedad entonces cita con el dermatólogo, traer el reumatólogo, yo les daba más posibilidades, pues cómo te acabo de decir cuarenta y tres años con la enfermedad yo aprendí a conocer, hablar de ella, saber cómo la manejo". E13

Otra situación que aflige al paciente es tener una enfermedad que aunque se controle no se observa mejoría, como son las enfermedades crónicas, lo cual le genera tristeza; sobre todo, cuando se da cuenta que el equipo de salud no le comunica la información adecuada.

"Él médico le dijo a mi hija, que ya eso (...) que hasta que la muerte nos separe, lo que tengo, que eso no se me va a quitar y que hay que es (...) entonces eso lo pone a uno muy triste, cierto? Entonces mi hija me dijo: No se preocupe mami, arriba de Dios no hay nadie, usted se puede aliviar, el hígado es un órgano que se regenera más fácil, de pronto si te alimentas bien. Ella me empezó y me animó, a mí me dejó muy triste, entonces yo pienso que decirle a uno esas cosas, como que le afecta, le baja a uno las ganas (...) "E10

\section{Sentirse incomunicado}

Hay que mencionar además, que los pacientes se sienten incómodos al no tener la facilidad para comunicarse con su familia, ya sea porque no tienen celular o porque no lo pueden manejar debido al desconocimiento causado especialmente por la edad. Es aquí donde añoran disponer de un teléfono fijo en la habitación para poderse comunicar. Aunque la institución cuenta con teléfono público en los pisos, no pueden acceder a éste, los pacientes, ya sea por su condición de salud y por la ubicación en el servicio; y en el caso de los cuidadores porque no quieren dejar solo al paciente.

"pero igual yo sí digo, para mí, como pa' todos los enfermos, como para mi mamá y para todos los enfermos debiera haber teléfono, para poder comunicarse ellos directamente con su familia y que ellos puedan la familia llamar y ellos contestar porque así es más fácil primero lo había, hace muchos años aqui lo habia, ese servicio si me parece muy importante asi tenga todo el mundo celular". E1

\section{Estando sin cuidador}

Algunos pacientes no tienen quien los acompañe durante la hospitalización por tener un grupo familiar reducido o porque sus familiares tienen responsabilidades laborales que les impiden acompañarlos en el hospital. Para quienes tienen la posibilidad de tener la compañía del cuidador familiar desearían que este se quedara durante todo el tiempo acompañándolos, pues se le tiene más confianza para pedirle ayuda cuando se requiere; es así como el no tener al cuidador genera incomodidad, resignándose a no disponer de su presencia y aceptando la situación aunque no lo quieran.

"Que él pueda estar conmigo aquí, acompañarme por la noche, porque uno a veces necesita alguna cosa, entonces ahí tiene a la persona, y la confian$z a ” . \mathrm{E} 10$

De igual modo, al no disfrutar de la compañía del cuidador familiar durante las 24 horas produce tristeza, no solo en el paciente, sino también en el cuidador, para quien por el vínculo afectivo le es doloroso dejar en el hospital a su familiar, sintiéndose culpable, al considerar que lo dejan tirado, aunque el paciente sea autónomo para realizar las actividades básicas.

"entonces yo me voy, pero solo Dios y yo sé cómo me voy jay no que con solo pensarlo cuando salgo de aqui me dan ganas de llorar!, pensar que la dejo, gracias a Dios ella está bien, que no pues como decir que me voy y la tengo que dejar (...) gracias a Dios ella se mueve y ella en la noche no se para, para nada, para nada, pero de igual manera ella es mi mamá y a mí me duele, el solo hecho de saber que esta tirada en el hospital sola, muy duro, es mиy duro". E3

\section{Resignación}

Hay que mencionar además, que los pacientes manifiestan resignación ante las condiciones que les ofrece la institución y sienten que no pueden reclamar porque son muchos pacientes los que requieren atención. Piensan que lo que hagan con ellos al estar enfermos está bien; además, al ver que el personal está ocupado prefieren no molestarlo y hacer lo que pueden teniendo en cuenta sus limitaciones.

"hay muchas cosas que no me gustan. Pero bueno, como uno está aquí a lo que hagan con uno, uno no puede reclamar nada y pues seriamos muchos para poder reclamar". E9

En definitiva, los pacientes terminan con el tiempo acostumbrándose a lo que les ofrece la institución, específicamente en lo relacionado con los enseres como son: la cama, la almohada y el no tener cobijas.

\section{Comparando servicios en la institución}

Los pacientes también expresan que en la institución hay diferentes opciones de habitación, las cuales son 
asignadas de acuerdo a la EPS al que esté afiliado. En este sentido las hay: individuales, compartidas para dos o tres pacientes, algunas son más amplias y cómodas y otras no.

"mi hija vio que de aquel lado hay otras mejores, más grandes, más cómodas" E9

"Si la habitación es grande como la de abajo que el baño sea para dos enfermos, igual se justifica, pero es que para cuatro iuy no eso es el colmo!’. E3

Hay que subrayar, que describen el servicio de urgencias como una mala experiencia y esperan que se les traslade pronto a una habitación; al respecto, muchas veces son atendidos en una silla y el suero colgado en un gancho, lo comparan con un servicio de otra región. Igualmente, expresan que el espacio es insuficiente para atender el número de pacientes que ingresan para recibir atención.

"porque estuve dos dias en la sala de urgencias, no por negligencia de la parte administrativa, sino por el hacinamiento y quizás por la falta de espacio locativo en dónde pueden albergar los pacientes que en ese momento estamos solicitando acceder al servicio médico". E15

Además, no solo la habitación se asigna según la EPS al que esté afiliado el paciente, sino que también en urgencias se le ubica dependiendo de la EPS que tenga; es decir, que las condiciones no son iguales para todos, pues se disponen de salas más cómodas frente a otras incómodas. De ahí, que algunos pacientes sean ubicados en sillas plásticas, en cubículos que describen como incómodos, poco ventilados, con aire acondicionado que no funciona y con la luz prendida todo el tiempo.

"la sala 7 es urgencias, sala de urgencias normal con personas de toda clase, él no durmió, es una silla plástica. Al lado, son unos cubículos demasiado incómodos, el calor es insoportable, eso enferma más al paciente. Yo les decía y decían que el aire estaba malo, que no podían apagar la luz, bueno, una cantidad de cosas.. E12

Otro rasgo que mencionan los pacientes hace referencia a la otra sala de urgencias, donde se dispone una enfermera para atender a cinco pacientes como máximo, lo que indica que el servicio es personalizado; por tanto, es un buen servicio.

urgencias del piso cuatro que hay una sala también para los de la universidad y tiene una enfermera solo para la salita, son si mucho cinco pacientes, si acaso, que nunca nos han tocado los cinco, es per- sonalizado, es muy bueno .. E12

Por otro lado, los pacientes se quejan de que en la UCI y la UCE hay mucho ruido, no hay acceso al baño, no hay televisor, aunque reconocen que es un servicio donde la atención es constante. Además, consideran que la habitación individual es como un pent-house, y la comparan con otras que no son tan agradables. El tener el baño para ellos es una maravilla.

"El ambiente. Si este lugar es muy agradable, muy diferente estar uno aqui a estar en la UCI, por allá todo miedoso, ¿en la otra que también es (...) cierto? UCI es una, UCE es la otra. Aquí por ejemplo hay una cosa que me pareció muy buena anoche, porque anoche apenas me pasaron, que no hacen tanta bulla:. E10

\section{La incomodidad del cuidador preocupa}

Igualmente genera en los pacientes incomodidad y preocupación al observar que el familiar que los acompaña deba estar sentado en una silla toda la noche.

"Si, ellos ponen una silla y ahí permanecen toda la noche sentados (...). Pues no me parece bien, porque pues ellos también son humanos, para estar uno toda la noche sentado en una silla, no es, porque pues el acompañante no viene a quitar a consumir nada, sino a hacerle la compañía a uno, porque lo necesita uno. Que no debiera de ser asi'”. E9

En consecuencia, el paciente elige que su cuidador se vaya a dormir a casa, evitando así el tener que verlo dormir en el piso sobre unas sábanas; es por tal razón que prefiera quedarse solo, si su situación de salud se lo permite.

"Toda la noche me llama, pero también muy injusto que ella durmiera allá en una sábana estirada en el suelo y le toca trabajar, entonces ahí sí más incómoda me siento yo. En la casa pues bueno, me siento incómoda porque no la tengo, pero me siento bien porque ella se va, pero que más toca”. E3

También consideran que el espacio de la habitación es muy estrecho para albergar pacientes, cuidadores y personal de enfermería; es por eso que cuando se requiere ingresar a la habitación para realizar las actividades de cuidado, el cuidador se debe salir y termina incomodándose.

"a mí me afecta porque, porque ella en esa silla, en esa incomodidad tan horrible toda una santa noche, eso cansa mucho y hay y hay veces de que están por 
ahí sentaditas y ya entran a tomarle a uno la presión $y$ tienen que coger su sillita e irse, salirse para poder quedar amplio, entonces una cosita de que no fuera tan estrecho, porque entonces si está la hija de la señora y la hija mía y se cuadran a cuidarnos de noche a asistirnos, a acompañarnos y llegan a tomarnos la presión, entonces todas dos tienes que coger sus sillitas y salirse porque no caben”. E5

Con respecto a los cuidadores hay que precisar que les incomoda el que no puedan usar del baño en las habitaciones individuales, pues deben salir a los baños que están ubicados cerca a las salas de espera y en muchos casos les disgusta el dejar solo a su familiar enfermo.

\section{"la otra vez que él estuvo hospitalizado, dizque que no se podía utilizar ese mismo (el baño) hay que sa- lir, pero imagínese si uno sale en esas y pasa algo y que ¿no? no aquí en el corredor sí, pero sale uno y mientras que uno sale pues a salir a buscarlo por allá". E12}

Otro factor a tener en cuenta es que para los cuidadores les es difícil suplir la necesidad de alimentación con la oferta que les ofrece la institución, motivo por el cual deben salir para buscar sitios que queden cerca, donde puedan comer.

"pero si en este momento la incomodidad es esa y la de la alimentación del acompañante porque muchas veces ella tiene que salir y muchas veces no encuentra nada por ahi”. E14

\section{Alimentación que incomoda}

Para algunos pacientes la comida de la institución la perciben como desagradable, ya que al momento de recibirla esta fría, aunque terminan comiendo lo que se les ofrezca, porque al tener hambre hay que comer lo que sea.

"Lo que no le encuentro como gracia, es que la comida es muy fría, no es muy buena, la comida, vienen al medio día, le traen la sopa a uno helada, pues eso no es agradable, una comida fría es muy maluco ${ }^{\circ}$. E11

Si bien es cierto que la dieta que se ofrece a los pacientes es la prescrita para su condición de salud, y que se espera sea la misma que deben consumir en la casa, algunos la consideran que no es buena porque es insípida, sin sal, no provoca.

"Ah no, si es la comida (...). La comida muy mala. Sí, pues no es mala, sino que uno enfermo, es la co- mida que uno requiere, pero no (...). No me gusta la comida de acá". E2

De manera similar, los pacientes se quejan respecto a que los alimentos les son dejados por el personal de alimentación sobre la mesa, cuando en ocasiones requieren ayuda y no tienen quien les colabore. Sin embargo, algunas personas del servicio de alimentación identifican la necesidad de ayuda y colaboran. Asimismo, destacan que las actividades de cuidado como la administración de medicamentos venosos les impide comer a la hora que llega el alimento y deben esperar para comer más tarde.

"A veces ella entra la alimentación y estoy ocupado con el asunto de medicamentos y no puedo movilizar las manos a ver hace rato me tenía como no podía mover las manos en el desayuno me dijo "tranquilo que yo espero vuelvo en tantos minutos con la comida”. E15

En relación con los pacientes que no son de la región donde están hospitalizados, les hace pensar que no serán bien atendidos y que pasaran trabajos.

"yo lo que temía era que sí me hospitalizaban iba a pasar trabajo, pero trabajo por la alimentación porque es muy difícil pero ahi vamos, vamos pasando el tiempo". E15

Otros pacientes expresan que no quedan satisfechos con la cantidad de comida que se les brinda, más cuando la dieta está en función del tratamiento que tienen; no obstante, se les permite comer lo que deseen y traerlo de la calle si su condición clínica lo permite.

"yo en realidad no tengo mucho problema con la alimentación, antes cómo les cuento por lo de la anemia debo estar comiendo bien, yo aqui me he dado el gusto de preguntarle a la muchacha mira, eh no me sentí con el almuerzo, será que de pronto (...) lo que les estoy contando es real, ¿será que me puedo comer una hamburguesa? (...) sentí la confianza de decirle miré que no quedé satisfecho ¿puedo comer algo más, la muchacha por supuesto averigua y me dice si". E13

\section{Infraestructura que incomoda La habitación compartida}

Al mismo tiempo incomoda a los pacientes el que el espacio de la habitación sea tan estrecho para albergar dos camas, lavamanos, mesas; al respecto sienten que no se puede caminar dentro de la habitación, es por eso que todos los visitantes no pueden estar en la habita- 
ción. Agregan, que la habitación no les permite tener privacidad y esto les incomoda. También expresan que al no tener donde guardar las pertenencias, hace que el espacio se vea desordenado, al colocarlas sobre la mesa o el sillón.

"Lo que más a mí me ha incomodado de todo esto, la habitación, el lavamanos dentro del cuarto no debia de ser, muchas cosas, no me parece, de que el lavamanos ahi tan estrechito, las mesitas, todo y no allá uno por donde caminar, entonces no me parece muy bueno, yo lo único que le encuentro malo aquí es la habitación y eso, porque la privacidad es lo más importante que hay". E9

\section{El baño compartido}

Algo semejante ocurre cuando el baño se tiene que compartir entre pacientes y cuidadores, pues no solo lo utilizan dos pacientes, sino que en muchas ocasiones son cuatro, más cuando el cuidador hace uso de éste. Lo describen como horrible. Compartir el baño lo consideran como no higiénico.

“los baños son compartidos, por ejemplo, cuando le dan a uno una pieza de dos, aquí hay dos y en la que sigue hay dos, entonces tiene puerta por aquí y tiene puerta por allá. E14

"que un baño sea para dos habitaciones, donde hay, por ejemplo, dos y dos, cuatro, más el acompañante que haya, ya son 6. Un solo baño”. E9

En consonancia con lo que se dijo más arriba, los pacientes tienen que madrugar a bañarse, pues al compartir el baño con los de la habitación contigua, quienes muchas veces lo tienen ocupado, deben esperar.

"Lo que allá, uno tenía que esperar que desocuparan el baño o bañarse más ligero”. E11

\section{Cerrar el baño incomoda}

Para entrar al baño es necesario ponerle seguro a la puerta para que los pacientes de la otra habitación no entren; cuando en algunos casos se les olvida quitar el seguro, ocasiona que tanto los pacientes o cuidadores deban ir hasta la otra habitación para solicitar la apertura de la puerta, lo cual les genera incomodidad.

"Me tocaba que abran o que venga alguien para yo decirle, y sí, tocaba que viniera alguien, dieran la vuelta (...) ahí venga abra la puerta del baño que la dejaron cerrada”. E8

Como resultado, los pacientes consideran que el com- partir el baño no les da privacidad; lo que los obliga a solicitar que el baño sea para una sola habitación.

entonces ese es el problema, muchas veces uno entra al baño y se le olvidó abrirla, entonces ya los de enseguida se incomodan y eso no debería de ser así, pues cada pieza debería de tener su baño“. E14

Otros aspectos que les incomoda son: la ducha, la escasez de agua caliente, los malos olores y la falta de limpieza de la habitación

"Pues mal, porque es un chorrito que (...) se demora uno mucho tiempo para bañarse porque es un chorrito muy poquito, si se siente, si me siento incómoda, incómoda, incómoda, tiene uno que quedarse mucho rato y es muy incómodo para uno (...) vienen y hacen el aseo a medias, vienen a hacer el aseo muy tarde, demasiado tarde imagínese ese baño lleno de pelos. Lleno de pelos y ayer, principalmente ayer había mucho papel en el piso”. E3

\section{Sin elementos básicos}

De manera semejante algunos pacientes manifiestan que deben llevar la cobija y la almohada, ya sea porque en la institución no hay para suminístrales o porque las que les dan no son suficientes. Otros expresan que las cosas de aseo personal tienen que llevarlas, lo cual es entendible; no obstante, les llama la atención que antes la institución les preveía específicamente de jabón y papel higiénico.

"Pues a mí sí me hace falta la cobija, lo que pasa es que hay que traerla porque aqui no hay cobijas (...). Pues aqui hay que traer de todo: jabón, las cosas de aseo personales, hay que traerlas". E2

\section{Haciendo sugerencias}

Lo dicho hasta acá permite que algunos pacientes y cuidadores sugieran cambios en la institución de tal forma que les permita sentirse cómodos al disponer de: habitaciones individuales, un baño por habitación, el suficiente personal de servicios generales para asear las habitaciones con más frecuencia en el día. De igual forma recomiendan que la alimentación para el acompañante sea favorable, cuando se paga por el servicio de salud; además, solicitan una silla aparte del sofacama en el cuarto individual, para que cuando el cuidador esté acostado y el paciente quiera sentarse lo pueda hacer en la silla.

“En cambio, el baño debería ser para un pacien- 
te o mínimo para dos e incluso la habitación (...). Que me gustaría, que generaran más empleadas del aseo para estuviera más pendiente de cada pieza, porque es que igual como le digo hay muchas bacterias, hay muchas cosas entonces requiere como más aseo, pero en cambio el aseo en un solo día para una habitación no, no se justifica”. E3

\section{Discusión}

Esta investigación permite entender la comodidad desde la perspectiva del paciente, donde no solo el entorno hay que tenerlo en cuenta, sino que también hay que privilegiar lo físico, lo social, lo emocional, lo sociocultural puesto que son factores que inciden directamente en su comodidad durante el tiempo de hospitalización.

Al respecto, Kolcaba opina que para que haya comodidad se deben considerar las necesidades de alivio, tranquilidad y trascendencia satisfechas en cuatro contextos: físico, psicoespiritual, sociocultural y ambiental (10). El autor explica que se debe aliviar el malestar en los pacientes; ofrecerles tranquilidad para la comodidad en la mente y el cuerpo; estimular la trascendencia para que la persona esté por encima de sus problemas o dolor. En cuanto a los contextos, el físico tiene que ver con la atención a las sensaciones corporales; el psicoespiritual a la consciencia interna del yo, como: autoestima, auto-concepto, sexualidad, significado de la vida; $y$, el social a las relaciones interpersonales, familiares y sociales (24).

Desde otro punto de vista, Ruydiaz y col., expresan que la hospitalización es un evento que causa ansiedad, estrés, depresión, alteraciones en el bienestar y dificultades para la interacción social, circunstancias que pueden estar relacionadas directa o indirectamente con la enfermedad; ante esto, se hace necesario aumentar la comodidad, la comunicación y la atención a fin de contribuir en la disminución de las alteraciones emocionales (25).

Por otro lado, Silva y col., manifiestan que se deben buscar medidas que permitan el bienestar del paciente como son: la iluminación adecuada, el control de ruidos, las sábanas limpias y la limpieza del ambiente. La mejora en el ambiente hospitalario influye adecuadamente en la percepción del paciente con respecto al cuidado brindado por el profesional de salud, lo que lleva a plantear mejoras en la organización, con lo que se logrará un ambiente confortable e íntimo para los pacientes y familiares (26).

Se debe agregar que Borre y Vega encontraron en su estudio que los aspectos tangibles e intangibles mejor valorados por los pacientes son: la apariencia del personal, el sistema de señalización en los servicios, la tecnología, la puntualidad, la confianza, la amabilidad, la preparación académica, el trato personalizado y la capacidad para comprender las necesidades del paciente. Según estos autores, dentro de lo medianamente favorable están: la información proporcionada, el interés por cumplir lo que se promete y la rapidez en la atención. Los aspectos peor valorados fueron: la apariencia y comodidad de las habitaciones, el interés en la resolución de los problemas, el tiempo de espera y la actitud de disposición (27), situación similar a lo encontrado en esta investigación.

De manera semejante a los hallazgos que se obtuvieron en este estudio, los hallados por Ruiz y col., señalan que el acompañamiento y la visita de la familia son fuente de tranquilidad y satisfacción, pues el apoyo familiar y los amigos les facilita la estadía, les brinda serenidad, compañía y comodidad. El aporte desde el ámbito social se enmarca en la importancia del apoyo de la familia y amigos para alcanzar la comodidad y el bienestar, porque los hace sentir bien, amados y les da fuerza para seguir adelante (28).

Agregan los autores que la restricción física por dispositivos instalados, los medicamentos $\mathrm{y}$, principalmente el dolor, hacen que los pacientes pierdan la capacidad de realizar movimientos libremente. Esta falta de autonomía llega a originar irritabilidad y disgusto, por no poder suplir necesidades básicas, creándose la percepción de dependencia de otra persona para ejecutar movimientos básicos (28).

Por su parte Garcez-Ramírez y Galvis consideran que la presencia y sensación de dolor están relacionadas con el malestar y su alivio es el objetivo inmediato de las intervenciones de la enfermería. Para ello, -agregan- hay que promover el control del dolor mediante la administración de terapias, masajes y cambios de decúbito, que se consideran proveedores de comodidad y bienestar. Además de las estrategias utilizadas por las enfermeras, también aparecen formas y medios de brindar comodidad en momentos particulares, que incluyen el primer contacto, el momento del cuidado de la higiene, el acicalamiento y la visita de la familia (24).

De otro lado, Cardoso R y col., manifiestan que la pérdida de autonomía es uno de los principales problemas que enfrentan no sólo las personas mayores sino también la mayoría de los pacientes hospitalizados. Este proceso de institucionalización implica aislamiento social, imposición de diferentes grados de inmovilidad, exposición a riesgos, adaptación al ambiente hospitalario (con restricciones y reglas), que repercuten en un 


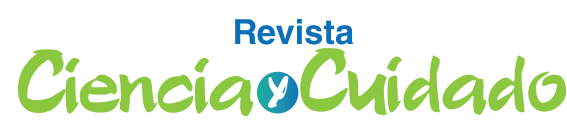

Scientific Journal of Nursing mayor peligro de deterioro funcional y un aumento de la dependencia. Las estrategias de confort promovidas por la enfermería deben ser percibidas y planificadas de acuerdo con el deseo de la persona hospitalizada (29).

De acuerdo con Ponte y col., los pacientes hospitalizados en la unidad de urgencias padecen situaciones de incomodidad -similares a las encontradas en este estudio- con relación al servicio de urgencias como son: que la unidad de urgencias tenía una ocupación superior a su capacidad; pacientes ubicados en sillas por tiempo indeterminado; demora en la realización de exámenes; aumento de la angustia; información imprecisa; necesidad de acompañamiento familiar; ruido del ambiente; $\mathrm{y}$, falta de privacidad. También admiten que es fundamental la satisfacción sobre las necesidades de confort en cuanto a: alivio del dolor, adecuación de la cama, satisfacción de las necesidades de sueño y descanso, apoyo y buena relación con el equipo de salud, presencia de un familiar durante la hospitalización, satisfacción con la limpieza del medio ambiente, disponibilidad de medicamentos y procedimientos que solucionaron su problema de salud. Los hallazgos revelan que la percepción de comodidad es de tipo individual (30).

Garcés y Col, por su parte, consideran que otro actor que promueve la comodidad es la familia, puesto que es muy significativa, al representar para el paciente una gran ayuda, así como el apoyo asociado al contexto sociocultural. La situación de enfermedad crónica y hospitalización es una etapa de la vida que provoca un gran impacto emocional en el paciente y su familia, y el momento de las visitas les brinda consuelo. Cuando están presentes los familiares y personas significativas, se sabe que se intenta crear un ambiente personalizado, en donde muchas veces la presencia de objetos personales del paciente, aumentan la cercanía y el cariño familiar. A su vez la adopción de actitudes afectuosas por parte de las enfermeras permite establecer una relación de ayuda, dada su función facilitadora, lo que implica el que se reconozca lo significativo que es para cada paciente esta actitud permitiéndole así un mayor estado de comodidad (24).

\section{Conclusiones}

En conclusión, el significado de la comodidad para el paciente con ECNT que se encuentra hospitalizado va más allá de lo que se percibe en el entorno hospitalario. Es por eso, que los aspectos físicos, emocionales, sociales y culturales se les considere como esenciales a la hora de hablar de comodidad. Además, la comodidad es un componente del cuidado que debe ser suplido por la enfermera, no solo con el apoyo del personal auxiliar, sino también con el concurso de todas las personas que hacen parte del equipo de salud. También, es importante impulsar las formas y los medios que sirvan para brindar comodidad a los pacientes hospitalizados, con el fin de lograr su mayor estado de bienestar durante la estancia hospitalaria. A su vez las instituciones hospitalarias deben escuchar la voz del paciente con el objeto de hacer las adecuaciones pertinentes para que la experiencia de hospitalización sea grata y lo menos traumática posible para los pacientes con enfermedad crónica.

\section{Sugerencias y recomendaciones}

De conformidad con todo lo planeado anteriormente, es necesario diseñar estrategias de sensibilización para el personal de salud y especialmente de la enfermería, que permitan un cambio que no se limite a una perspectiva meramente instrumental, sino que se oriente hacia una mirada más humana de las necesidades de confort de los pacientes y cuidadores familiares en el ámbito hospitalario.

\section{Referencias Bibliográficas}

1. Arokiasamy P, Uttamacharya, Kowal P, Capistrant BD, Gildner TE, Thiele Eet al. Chronic Noncommunicable Diseases in 6 Low- and Middle-Income Countries: Findings From Wave 1 of the World Health Organization's Study on Global Ageing and Adult Health (SAGE). Am J Epidemiol [Internet]. 2017 Mar; [Consultado 2020 Apr 13]; 185(6):414-28. Disponible en: https://doi.org/10.1093/aje/kww125

2. Vélez-Londoño LM, Hernández PA, Silva CE, Giraldo EH, Moreno A, Cifuentes MG, et al,. Estructura de la morbilidad en el departamento de Antioquia [Internet]. Capitulo 3 [Consultado 2020 Abr 3]. Disponible en: https://www.dssa.gov.co/index.php/descargas/250-capituloestructura/file

3. Republica de Colombia. Departamento Nacional de Estadística. Proyecciones de población [Internet]. [Consultado 2020 Abr 26] Disponible en: https://www.dane.gov.co/index.php/estadisticas-por-tema/demografia-y-poblacion/proyecciones-de-poblacion 
4. Tejada-Pérez II. No es fácil estar 24 horas en una cama: confort del paciente con sedación en UCI. Aquichán. 2017; 17(4): 380-89. https://doi.org/10.5294/aqui.2017.17.4.2

5. Moreno-Monsiváis MG, Interial-Guzmán MG. Percepción del paciente acerca de su bienestar durante la hospitalización. Index Enferm. 2012; 21(4): 185-89. http://dx.doi.org/10.4321/S1132-12962012000300002

6. Kolcaba KY. La teoría del confort. En: Ann Marriner Tomey, Martha Raile Alligood. Modelos y teorías en enfermería. 7 ed. Barcelona: Mosby Elsevier; 2011:706-20.

7. Tosun B, Aslan Ö, Tunay S, Akyüz A, Özkan H, Bek D et al. Turkish version of Kolcaba's immobilization comfort questionnaire: A validity and reliability study. Asian Nurs Res [Internet]. 2015 [Consultado 2020 Apr 13]; 9(4): 278-84. Disponible en: https://www.sciencedirect.com/science/article/pii/S1976131715000675

8. Romero-Massa E, Contreras-Méndez IM, Moncada-Serrano A. Relación entre cuidado humanizado por enfermería con la hospitalización de pacientes. Hacia promoc. salud. 2016; 21(1): 26-36. http://dx.doi.org/10.17151/ hpsal.2016.21.1.3

9. Flórez-Flórez ML. Comodidad del paciente hospitalizado en un servicio de cirugía cuando se proveen medidas de comodidad que involucran a la familia. Actual Enferm [Internet]. 2001 Jun; [Consultado 2020 Abr 20]; 4(2): 8-15. Disponible en: https://pesquisa.bvsalud.org/portal/resource/pt/lil-324761

10. Pontífice-Sousa PC, Dourado-Marques RM, Ribeiro MP. Geriatric care: ways and means of providing comfort. Rev Bras Enferm [Internet]. 2017 [Consultado 2018 Mar 3]; 70(4):830-37 Disponible en: http://dx.doi. org/10.1590/0034-7167-2016-0636

11. Pereira C, Merces C, Pita Lopes RO, Felix Souza J, Souto J, Gomes-Brandâo MA. Análise do conceito de conforto: contribuições para o diagnóstico de disposição para Conforto melhorado. Esc. Anna Nery Rev Enferm [Internet]. 2020 [Consultado 2020 Oct 26] ; 24(2): e20190205. Disponible en: https://pesquisa.bvsalud.org/ portal/resource/pt/biblio-1090266

12. Goetz JP, LeCompte MD. Etnografía y diseño cualitativo en investigación educativa. Madrid: Morata; 1988.

13. Cotán-Fernández A. El método etnográfico como construcción de conocimiento: un análisis descriptivo sobre su uso y conceptualización en ciencias sociales. Márgenes (Málaga) 2020; 1(1): 83-103. https://doi.org/10.24310/ mgnmar.vli1.7241

14. Boyle J. Estilos de etnografía. En: Janice Morse J. Asuntos críticos en los métodos de investigación cualitativa. Medellín: Universidad de Antioquia; 2003: 185-211.

15. Troncoso-Pantoja C, Amaya-Placencia A. Entrevista: guía práctica para la recolección de datos cualitativos en investigación de salud. Rev. Fac. Med. [Internet]. 2017 [Consultado 2020 Abr 15]; 65(2): 329-32. Disponible en: http://dx.doi.org/10.15446/revfacmed.v65n2.60235

16. Caïs J, Folguera L, Formoso C. Investigación cualitativa longitudinal. Madrid: CIS- Centro de Investigaciones Sociológicas; 2014.

17. Galeano-Marín ME. Registro y sistematización de información cualitativa. [Internet] Medellín: Fundación Universitaria Luis Amigo; 2001 [Consultado 2020 Mar 12] Disponible en: http://aprendeenlinea.udea.edu.co/lms/ moodle/pluginfile.php $/ 206102 / \mathrm{mod}$ resource/content $/ 0 /$ Registro_y_sistematizacion_de informacion_cualita$\underline{\text { tiva.pdf }}$

18. Coffey A, Atkinson P. Encontrar el sentido a los datos cualitativos: estrategias complementarias de investigación. Medellín: Universidad de Antioquia, Facultad de Enfermería; 2003.

19. Samaja J. La triangulación metodológica (Pasos para una comprensión dialéctica de la combinación de métodos). Rev Cubana Salud Pública [Internet]. 2018 [Consultados 2020 Abr 20]; 44(2): 431-43. Disponible en: http:// 
Scientific Journal of Nursing

$\underline{\text { scielo.sld.cu/pdf/rcsp/v44n2/1561-3127-rcsp-44-02-431.pdf }}$

20. Arias-Valencia MM, Giraldo-Mora CV. El rigor científico en la investigación cualitativa. Invest Educ Enferm. 2011; 29(3): 500-14.

21. Republica de Colombia. Ministerio de Salud. Resolución $\mathrm{N}^{\circ} 008430$ de 1993, por la cual se establecen las normas científicas, técnicas y administrativas para la administración en salud. Santafé de Bogotá: El Ministerio 1993.

22. República de Colombia. Congreso de Colombia. Ley 266 de 1996, enero 25, por la cual se reglamenta la profesión de enfermería en Colombia y se dictan otras disposiciones. Diario Oficial No. 42.710. Bogotá: El Ministerio; 1996.

23. República de Colombia. Congreso de Colombia. Ley 911 de 2004, por la cual se dictan disposiciones en materia de responsabilidad deontológica para el ejercicio de la profesión de Enfermería en Colombia; se establece el régimen disciplinario correspondiente y se dictan otras disposiciones. Diario Oficial No. 45.693. Bogotá: El Ministerio; 2004.

24. Garcez-Ramírez GL, Galvis Y. Medidas de comodidad que brinda la enfermera al adulto con deterioro de la ambulación. Cuidado y ocupación humana. [Internet]. 2017 [Consultado 2020 Jun 12]; 6:58-67. Disponible en: http://revistas.unipamplona.edu.co/ojs_viceinves/index.php/COH/article/view/3459/

25. Ruydiaz-Gómez KS, Saldarriaga-Genes G, Fernández-Aragón S. Satisfacción del usuario: un reto para la calidad del cuidado. Cienc Sal Virt [Internet]. 2018 [Consultado 2020 Jun 12] ; 10(1): 49-61. Disponible en: https:// $\underline{\text { dx.doi.org } / 10.22519 / 21455333.969}$

26. Silva J, Córdova R, Vergaray S, Palacios V, Partezani R. Percepción del paciente hospitalizado respecto a la atención de enfermería en un hospital público. Enferm Univ [Internet] 2015 [Consultado 2020 Jul 20]; 12(2):80-7. Disponible en: https://www.sciencedirect.com/science/journal/16657063/12/2

27. Borré-Ortiz YM, Vega VY. Calidad percibida de la atención de enfermería por pacientes hospitalizados. Cienc. Enferm. [Internet]. 2014 [Consultado 2020 Oct 27]; 20(3): 81-94. Disponible en: http://dx.doi.org/10.4067/ $\underline{\mathrm{S} 0717-95532014000300008}$

28. Ruiz-Góngora MI, Díaz-Heredia LP. Comodidad del paciente en una unidad de cuidado intensivo cardiovascular. Av Enferm. [Internet]. 2018 [Consultado 2020 Abr 23]; 36(2): 188-96 Disponible en: http://www.scielo.org. co/pdf/aven/v36n2/0121-4500-aven-36-02-188.pdf

29. Barreto-Cardoso R, de Araujo-Pacheco ST, Pereira-Caldas C, Alfradique de Souza P, Pereira-Peres PL, Rodrigues-Nunes MD. Pratica confortadora ao idoso hospitalizado à luz da bioetica. Rev. Bioét. [Internet]. 2019 Dec [Consultado 2020 Oct 1]; 27(4): 595-99 Disponible en: https://www.scielo.br/pdf/bioet/v27n4/en 1983-8042bioet-27-04-0595.pdf

30. De Azevedo Ponte KM, Santiago-Bastos FE, García de Sousa J, Miranda-Fontenele MG, Cassimiro-Aragäo O. Comfort requirements of patients assited by the urgency and emergency service implications for the nursing profession. Cuidado e Fundmental [Internet]. 2019 Jul-Sepd[Consultado 2020 Oct 1]; 11(4): 925-30 Disponible en: http://dx.doi.org/10.9789/2175-5361.2019.v11i4.925-930 